\title{
A Critical Discourse Analysis of Pakistani and Indian Budget Speeches
}

\author{
Sidra Ahmed (Corresponding author) \\ Dept. of English Linguistics, GC University, Faisalabad, Pakistan \\ E-mail: muntaha1466@gmail.com \\ Dr. Rashid Mahmood \\ Dept. of English Linguistics, GC University, Faisalabad, Pakistan \\ E-mail: ch.raashidmahmood@gmail.com \\ Dr. Shahbaz Arif \\ Dept. of English Linguistics, GC University, Faisalabad, Pakistan \\ E-mail: drshahbazarif@gmail.com
}

\begin{abstract}
This study is a Critical Discourse Analysis (CDA) of Pakistani and Indian budget speeches. Two specialized corpora, Pakistani Budget Speeches (PBS) and Indian Budget Speeches (IBS), from 2009 to 2012 of both the countries were compiled. This research explored the hidden meanings through the study of Parts of Speech (POS) which were conveyed in budget speeches. These POS were limited to nouns (singular and plural), pronouns, adjectives (general), and verbs (present/past/modal). This study develops the insight that budget is declared having multiple meanings behind the statement. The study concludes that government declares the budget having some similarities and differences with other countries but hidden meanings behind the declaration is a fixed phenomenon of budget discourse.
\end{abstract}

Keywords: CDA, POS, Corpus Driven, Budget Speeches, Politics,

\section{Introduction}

CDA is a type of discourse analytical research that mainly studies social power manipulation, dominance, inequality by text and talk in both the social and political setting. Luke (1997) opines that to set the power of the written and spoken discourse, CDA is necessary for unfolding, interpreting, analysing, and evaluating social life reflected in text. It analytically discovers often cloudy relationships between discursive practices, texts, and events and wider social and cultural structures, relations, and processes. Critical language study examines social relations in a technique which emphases upon their linguistic features and which show their usually hidden elements in the system of social affairs along with hidden possessions they might have upon that system (Fairclough, 1993).

Politics obviously have substantial and non-linguistic aims and generalization that they control the delivery of resources, in a concrete as well as nonconcrete sense, in a given society. According to Schaffner (1996) "political discourse is thematic because its topics are primarily related to politics such as political activities, political ideas and political relations" (p.201). Discourse experts classify two approaches to deal with this subject of politics and language which are descriptive and critical. Descriptive approach depends on describing the linguistic strategies and the verbal performance of politicians and sometimes their ideology behind the utterances. On the other hand critical methods include social theories which have the quality to deal with the association between language and power, regulations as well as supremacy and instructions of discourse (Chilton, 2003).

Political professions, which have the function of arbitrating between the citizens and authorities, perform the functions to produce texts planned to persuade and to influence an institutional power. Political language is fundamentally used as an influential device in appealing the support as well as the harmony of the public and the nation policymakers. Political leaders, who deliver public speeches within the national settings, often have a tendency to control language or genre to achieve the political benefit, sustain power, and avoid responsibility. Idiagbon (2010) involves CDA to analyse the patterns of language and describes that how the language is used by the politicians. Researcher focuses that the consciousness should be awaken of every reader who is reading political discourse, because utterances in the political campaign do not give neutral and true statement. Political speeches, which are delivered in different settings, perform various functions in a set of cultural and social frameworks. Wang (2010) summarizes some features of Barack Obama's speeches that he used simple words and short sentences in speeches instead of difficult ones. His language is very easy and somehow colloquial as well. He concludes that through the use of modal verbs, present tense and first person pronouns Obama tried to reduce the distance between him and his audience. CDA not only involves the major factors of discourses but also the very minor issues can be handled through it, as Shayegh (2012) highlights that Barak Obama and Martin Luther King use WILL frequently in their speeches, which is indicating possibility arisen from reality. They 
want to create an impact on their people for their own position and as well as for the government in coming time. Various researches in CDA attempts to formulate or maintain an overall point of view of unity with the supremacy group. Politicians defend various ideas of social events and changes in their speeches with the use of discourse analytical terms for maintaining the status of government in front of people. Dickinson (2009) opines that political speeches share certain similarities and differences by which readers and listeners can understand the meanings of political discourse. Present study involves budget speeches to enlighten the characteristics of this discourse. Budget is considered very important document for all the people of county because from elite class to poor class everyone is bound to follow it for the next fiscal year. This study analyses the Pakistani and Indian budget speeches to explore the similarities and differences through parts of speech. The study uncovers the hidden meaning and gives awareness to common people about their representation in budget.

\section{Methodology}

The corpus driven methodology has been used for the Critical Discourse Analysis of Pakistani and Indian budget speeches. Four budget speeches from 2009 to 2013 have been combined into one complete text file. Corpus of Pakistani budget speeches has 4607 types and 30098 tokens. Types and tokens of Indian budget speeches are 5569 and 46147 respectively. The corpora have been syntactically tagged using CLAWS Tagger C7 Tagset. Antconc 3.2.1 has been used to study the concordance lines, to extract parts of speech (nouns, adjectives, verbs and pronouns) and to measure the frequencies. A list of keywords of both corpora has been prepared. Pakistani Written English (PWE) 2.1 million words general corpus has been used as a reference corpus. The data has been collected from the instances occurring in Pakistani Budget Speeches (PBS) and Indian Budget Speeches (IBS). Only those words of each category have been analysed which are found in both corpora and these words have been selected on the basis of keyword list and frequency. This research enlightens the differences and similarities between Pakistani and Indian budget speeches. Interpretations on the discussions have been made on the basis of usage of POS in PBS and IBS.

\section{Data Analysis \& Discussion}

\subsection{Nouns}

\subsubsection{Singular Nouns}

Noun is taken as the building block in parts of speech. Present study involved 'singular and plural' nouns to examine Pakistani and Indian budget speeches. Total number of singular nouns in PBS and IBS was 15439 but only eleven singular nouns were selected due to frequency and keyness.

Table 1. Singular nouns

\begin{tabular}{|l|l|l|}
\hline Singular Nouns & Ind & Pak \\
\hline Government & 211 & 446 \\
\hline Development & 123 & 186 \\
\hline Growth & 114 & 134 \\
\hline Economy & 76 & 122 \\
\hline Investment & 67 & 56 \\
\hline Agriculture & 54 & 66 \\
\hline Energy & 24 & 98 \\
\hline Finance & 52 & 32 \\
\hline Health & 39 & 64 \\
\hline Inflation & 27 & 58 \\
\hline Crisis & 24 & 22 \\
\hline
\end{tabular}

The study showed that above mentioned all 'singular nouns' have relation to each other. Present study pointed out that 'government' is responsible for budget declaration. Government takes steps to establish 'economy' and economy has direct influence of 'development' and 'growth' of every department and sector. In budget 'development' and 'growth' is mentioned in every department as 'agriculture', 'energy', 'finance' and 'health' to show their progressive situation. Developmental condition of these departments plays a vital role in establishment of economy. In budget not only growth and development is mentioned but 'inflation' and 'crisis' in every sector are also shown. Results have shown that PBS uses all these nouns with high and low frequency but this corpus rarely mentions these nouns in a unified way. IBS, on the other hand, mentions these nouns showing connection among them. This corpus discusses the role of 'government' in every sector and mentions 'development', 'growth' and 'crisis' according to the need of information.

Results have revealed that the occurrences of 'government', 'development', 'Economy' and 'Energy' have more difference in frequency. The study reveals that both the corpora focus on 'government' and show some duties which are performed by government. BPS and IBS relate some other plans and policies with government, in similarities, and use 'government' to give positive impact to masses of their current government, which is 
responsible for budgets. IBS focuses some other important points as 'government's job of reduction of custom duty' , 'concentration on service', 'completion of different projects', 'creation of development program', 'government hospitals and medical department'. Results enlightens that the occurrence of 'government' is higher in PBS than IBS but this planned information is missing in PBS rather an informal and overuse of 'government' is found in speeches. Both the corpora mention 'development' in agriculture and economic scenario as a similar point but PBS and IBS have certain differences in the use of 'development'. PBS mentions development in 'dairy units', 'energy sections and petroleum department', while IBS declares 'development' for 'children', 'infrastructure cases', 'rural ministry and agriculture', 'urban and youth institution'. Both the countries have some schemes and programs for the sake of development in their countries but IBS announces its schemes with required attention and also mentions the target population of these schemes which could be able to use these facilities while PBS has its high occurrence but it does not deliver the information in detailed way.

Present study proves that short, easy and familiar nouns are used in PBS and IBS. CDA indicates that simple vocabulary is used to make the people feel that here is no distance between masses and government but these simple words have so many hidden meanings through which government achieves its goal. PBS and IBS use the nouns to deliver the information on similar and different trends about different issues as PBS conveys the facts which apparently seem very significant but present research uncovers those matters which are neglected and delivered in covert way. On the other hand, IBS directly conveys the whole picture regarding any issue but CDA exposes that the direct and indirect use of language gives a profound and philosophical impact on people to attract them.

\subsubsection{Plural Nouns}

Both the corpora have 5305 plural nouns. Present study chose ten plural nouns form keywords list which were more frequent. In the list of selected plural nouns 'projects', 'proposals', 'markets' and 'banks' have huge differences in PBS and IBS.

Table 2. Plural nouns

\begin{tabular}{|l|l|l|}
\hline & Ind & Pak \\
\hline Projects & 71 & 94 \\
\hline Proposals & 44 & 18 \\
\hline Markets & 46 & 28 \\
\hline Sectors & 36 & 46 \\
\hline Farmers & 40 & 24 \\
\hline Taxpayers & 31 & 42 \\
\hline Banks & 46 & 8 \\
\hline Schemes & 26 & 26 \\
\hline Efforts & 11 & 46 \\
\hline Facilities & 13 & 16 \\
\hline
\end{tabular}

These plural nouns have mutual relation to each other as in budget government tries to support common people but some group of people are consciously mentioned in budget. Various 'efforts', 'schemes', 'facilities', 'proposals' and 'projects' are introduced in budget to relief the masses. Present study has explored that 'taxpayers' and 'farmers' are frequently mentioned in both the corpora and mentioned as special group of people from masses. IBS openly declares schemes for 'taxpayers' and 'farmers' and also mentions the role of 'banks' in this regard. Both the corpora discuss 'tax proposals' and give a brief picture of their benefits. The condition of 'markets' and 'sectors' has great impact on the economy and in budget they are discussed with full attention to show their role in establishment of the country. Present study shows that these nouns have connection to each other and in budget this connection is taken into account to make the budget more expressive.

Results have shown that PBS and IBS have certain similarities in budgets using all plural nouns as both the corpora confidently discuss those 'projects' which are completed recently. PBS and IBS openly tell about new projects for different departments and due to 'energy usage' in all over the world both the corpora discuss power projects in the country. In differences PBS discusses developed, important and on-going projects for various departments while IBS declares the housing, infrastructure, pilot and storage projects. This corpus specifies the information by telling targeted population of these projects as projects for loans, roads construction, food park and ultra-mega power projects. Banks are very important to start projects, programmes, schemes and loan distribution. Banks not only serves governmental matters at national level but also works for collective packages of masses. PBS and IBS similarly discuss the role of 'commercial banks' in different sectors of their countries. Here is a huge difference in the occurrence of 'banks' in PBS and IBS which indicates that PBS does not have any significant role of banks. PBS discusses 'TFC facilities' and 'salary payments'. IBS provides the information about 'recapitalization', 'financial strengthening', 'to enhance the capacity of Regional Rural Banks', 'multiple lending from different banks', 'financial health', 'capitalisation' and 'capital requirements of Public Sector Banks'. this study highlights that PBS does not give this sort of specified information in budgets then how can 
the condition of banks be promoted.

In budget discourse the correct use of language is made sure because government wants to attain its goal but this job is done very carefully giving a positive picture of government's efforts to the common people. To attain this purpose, government introduces all sort of beneficial programmes for masses declaring different scheme, proposals, projects and facilities. The occurrence of these nouns depicts that IBS performs its duty very professionally to show connection among these plural nouns. This corpus mentions that government puts various efforts to facilitate farmers and taxpayers which show that government is really concerned to improve the condition of these groups of people. PBS does not deliver the information showing any connection among these nouns.

3.2 Adjectives

Adjectives modify the nouns by describing, identifying, or quantifying them. With the help of adjectives the specific characteristics of nouns can be examined. Present study explores the use of general adjective in PBS and IBS which were 6718 in the corpora. Below mentioned ten adjectives have been taken due to frequency.

Table 3. Adjectives

\begin{tabular}{|l|l|l|}
\hline & Ind & Pak \\
\hline National & 144 & 82 \\
\hline Economic & 49 & 112 \\
\hline Basic & 84 & 28 \\
\hline Current & 49 & 62 \\
\hline Agricultural & 30 & 66 \\
\hline Global & 50 & 16 \\
\hline Foreign & 37 & 28 \\
\hline International & 12 & 68 \\
\hline Manufacturing & 25 & 22 \\
\hline Political & 2 & 26 \\
\hline
\end{tabular}

Present study makes clear to the connection of selected adjectives that in political scenario 'global', 'foreign' and 'international matters are taken into account to maintain the 'national' situation of the economy. These adjectives have not direct relation to the budget declaration but they are necessary of budget genre to solve the national matters and to establish the situation of economy comparing with worldwide network. All the 'current' and 'basic' needs of the country are mentioned in budget. These adjectives show that which matters are focused by the government in every fiscal year. 'Agricultural' and 'manufacturing' departments have great influence on 'economic' condition on the country. That is why these adjectives are combined and mentioned in budget to present a visual picture of coming fiscal year.

Results have pointed out that occurrence of most of the 'general adjectives' is huge in IBS as compare to PBS which is the indication that IBS discusses the matters in more open and dynamic style rather PBS is not this much consistent in this extent. Present study not only deals with the combination of words (nouns and adjectives) to trace out the results rather it highlights the use of these words with their key characteristics in both the corpora as PBS discusses 'national assembly secretariat', 'provinces and parliament', 'creation of the national commission of human rights' and 'national economic council' while, On the other hand, IBS declares 'national investigation agency', 'funds', 'national knowledge network', 'research associations', 'colleges', 'universities' and 'literacy mission', 'sustainable agriculture', 'rural telephone facility', 'health mission' and 'national skill development corporation'.

Present study investigates that IBS shows connection mentioning these adjectives and conveys the information specifically using them with nouns. This corpus neither repeats the previous information covertly nor overtly. Results have highlighted that PBS has somehow same use of 'global', 'international' and 'foreign'. This corpus huge occurrence of 'political' but does not have its substantial or significant role in any extent which weakens the budget reliability. IBS regularly mentions 'agricultural' and 'manufacturing' departments conveying required information about them but PBS does not mention them showing their role in other sectors or economy establishment. All the selected adjectives are essential part of budget discourse through which the information becomes more authentic and reliable. The absence of these adjectives or their connection to each other not only presents a dull picture of budget but also makes the information artificial.

3.3 Pronouns

Present study investigates the functions which are performed by pronouns in PBS and IBS. Total pronouns were 2154 in the corpora bur five pronouns have been chosen from keyword list due to frequency. 
Table 4. Pronouns

\begin{tabular}{|l|l|l|}
\hline & Ind & Pak \\
\hline I & 501 & 166 \\
\hline Our & 124 & 540 \\
\hline We & 98 & 564 \\
\hline It & 55 & 122 \\
\hline Me & 10 & 66 \\
\hline
\end{tabular}

Results have enlightened that 'we' has been used for different purposes in both the corpora. PBS uses this pronoun for various concerns as this corpus uses 'we' for the entire 'government', 'party', 'nation, people, and country'. This kind of information indicates the unity of entire community. Presnet study exposes that PBS delivers positive information about government using 'we' and wherever any sacrifice is required PBS involves the people of the country and prepare them to face any kind of circumstances and government shows that 'we all' (government and people) will resolve the problems. IBS, on the other hand, uses 'we' just for 'government and party'. This corpus does not use 'we' for any serious issue. The occurrence of 'we' is more in PBS as compare to IBS. This factor highlights that PBS uses 'we' for different purposes but IBS just mentions the government's effort by using this pronoun.

The occurrence and use of first pronoun indicates that minister takes the responsibility of every action in budget. PBS has lesser occurrence of 'I' than IBS which apparently does not seem authentic in information because 'finance minister' is not taking the responsibility. Results highlights that PBS mentions 'our' having collocation with 'agriculture', 'armed forces', 'brothers' (people), 'agendas', 'business environment', 'citizens', 'economy condition', 'tax and trade' and 'efforts' (which are put by government). IBS addresses 'agricultural production', 'customs duty rates', 'economic performance', 'export processes', 'growth strategy', 'creative energies' (of farmers, entrepreneurs, businessmen, scientists) and 'society'. CDA reveals that in PBS and IBS the use of 'our' is securing current government's strategies for the country but IBS announces the budget on strong grounds. The purpose is to investigate 'it' is to see that which patterns have been mentioned in 'passive form' in both the corpora. CDA examines that both the corpora use 'it is' having collocation with 'expected and proposed' which produced very significant results. The study of 'me' is very short because PBS and IBS do not use it for any substantial purposes.

Present study has proved that other pronouns as 'we', 'our', 'me' and 'it' also convince and persuade the people. CDA exposes the use of these pronouns at various stages that where government uses them and for what purposes. Budget bounds the people for one fiscal year to make them united for nation, country, government and party that is why government presents itself very responsible using 'we' and to mention crisis 'we' is used for people. Budget discourse is designed according to the issues and situations of economy of the country and, to handle the state of affairs, government plans the budget having country situation and demands of people into account. To achieve this target government uses the language with covert meanings. CDA investigates all those hidden meanings and ideologies which are taken into account by the government to declare the budget.

3.4 Verbs

3.4.1 Modal Verbs

Modal verbs are complex phenomenon of English grammar. They play different roles and communicate various meanings. This research examines the use of modal verbs in Pakistani and Indian budget speeches. Total quantity of modal verbs in PBS was 828 and in IBS was 458. Individual quantity is mentioned in the following table.

Table 5. Modal verbs

\begin{tabular}{|l|l|l|}
\hline & Ind & Pak \\
\hline Will & 242 & 396 \\
\hline Would & 125 & 206 \\
\hline Can & 26 & 38 \\
\hline Shall & 27 & 32 \\
\hline May & 15 & 38 \\
\hline Must & 12 & 78 \\
\hline Should & 6 & 22 \\
\hline Could & 5 & 18 \\
\hline
\end{tabular}

Modal verbs have a great variety of communicative functions. All the above mentioned modal verbs cover the subjective attitude or statement of the speaker, who presents her/his personal opinion and relation with reality. Politicians use these verbs to hide the exact information from common people. In political speeches politicians manipulate the statements according to their own needs and they fulfill their objectives showing one side of the picture to masses. Results have shown that the occurrence of all modal verbs is high in PBS than IBS which indicates that PBS is more speculative than IBS which presents a picture that this corpus has overlapping 
meanings of budget declaration. This study discovers that less use of modal verbs is an indication that budget does not have ambiguities in statements and IBS fulfills this requirement efficiently. PBS asserts the announcements in complex sentences with the over use of modal verbs which do not give the clear meanings to the audience.

Modal verbs themselves have connection to each other. Speakers use different modal verbs to perform various functions within one situation. In budget genre these verbs accomplish the same duty thorough which government achieves its goal and takes support by modal verbs to control the current situation of the country. CDA has uncovered those unclear and hidden meanings in this corpus regarding modality. The information, conveyed through modal verbs, in both the corpora is more authentic in IBS than PBS as IBS delivers the direct information with solid reasons rather PBS does not declares in insightful way. Present study has revealed that both the corpora use modal verbs to attain the set objectives of government through budget.

3.4.2 Present form of Verb

Most of the selected verbs indicate improvement. Total number of first form of verb in PBS and IBS was 1207. The following verbs have been taken due to frequency.

Table 6. Present form of verb

\begin{tabular}{|c|c|c|}
\hline & Ind & Pak \\
\hline Propose & 275 & 24 \\
\hline Provide & 96 & 68 \\
\hline Increase & 81 & 96 \\
\hline Reduce & 40 & 54 \\
\hline Encourage & 22 & 22 \\
\hline Improve & 27 & 42 \\
\hline Ensure & 29 & 52 \\
\hline Address & 34 & 20 \\
\hline Inform & 15 & 0 \\
\hline Expect & 8 & 8 \\
\hline
\end{tabular}

The complete occurrence of present verb in PBS is 320 and in IBS 887. The research points out that the occurrence of present verb determines that IBS delivers the information having current situation of all issues in mind. This corpus conveys specified information to masses as compare to PBS. The study raises some questions here, that the use of lexical verbs shows that different action are being performed in the budget by government, but if the occurrence of verbs remained very short in entire budget then would the all required actions be performed by the government and if the government ignored such an important part of language then would it be fulfilling its duty by heart.

Budget is declared to inform the people about economy of the country. People are bound to obey all modifications mentioned in budget for coming fiscal year. Government takes steps to develop the situation of the country as well as common people. Government offers many schemes and programs using verbs as 'propose' and 'provide' their occurrence basically depicts the attention of government towards people. In budget masses is more concerned about its betterment. For this purpose, all the information is conveyed using the verbs as 'increase', 'improve' 'reduce' 'ensure' and 'encourage'. People develop so many expectations with budget and for this reason 'expect' is very important to analyze that for what purposes government uses it in budget. Results have pointed out that IBS uses 'inform' having high occurrence while PBS does not use it for once which indicated that budget is not declared giving complete information to the common people. The merged relation of these verbs to each other shows that they all are necessary in budget to convey the information in a conclusive way.

3.4.3 Past Form of Verb

PBS and IBS have 337 second form of verb. Both the corpora do not use second form very frequently. Not a single verb is used more than fifteen times in the corpora. It is noticeable that some selected verbs are second form of those verbs which have been studied as first as form of verb as provided, increased, rose and helped. 
Table 7. Past Form of verb

\begin{tabular}{|c|c|c|}
\hline & Ind & Pak \\
\hline Became & 4 & 8 \\
\hline Increased & 5 & 4 \\
\hline Made & 3 & 6 \\
\hline Provided & 5 & 6 \\
\hline Received & 5 & 4 \\
\hline Rose & 5 & 8 \\
\hline Took & 7 & 12 \\
\hline Came & 2 & 6 \\
\hline Brought & 2 & 10 \\
\hline Helped & 0 & \\
\hline
\end{tabular}

The occurrence of these verbs shows that they are not used frequently in PBS and IBS. Over all occurrence of 'second form of verb' in the corpora is very less. The results of these verbs are also not so convincing regarding their use in the corpora. 'Increased' and 'provided' are found as 'present form of verb' with sufficient occurrence but as 'second form of verb' they do not have any significant use. These verbs are only POS which do not have substantial role in PBS and IBS. Present study has pointed out that their use in budget genre just covers government side and defends it in front of people.

The study proves that less use of 'second verb' is the core feature of budget discourse that government consciously takes no notice of past year events and does not discuss the previous issues in current year rather future picture is displayed in front of people to take their minds in control. Pity on poor masses because they think that future plans will give them comfort but they really don't know what game is played with them every year. Results have uncovered the fact that no attention is paid towards last year promises made by government.

\section{Conclusion}

Present study has impartially attained the aim and objectives of exploring the hidden meanings of PBS and IBS. This study has enlightened that budget speeches are not declared neutrally rather so many underlying meanings work behind simple statements. This study has exposed all hidden meanings of both the corpora which were opaque for common masses.

It has also been claimed that PBS and IBS have certain similarities and differences in the usage of various POS. As PBS does not deliver essential information about various issues which is found in IBS in detail, for instance agriculture, education, health, economy crisis, medical and formers' betterment. IBS uses specified way to address each matter but PBS pays minor attention to those issues, without keeping in view that how important they are for country development. Furthermore, PBS declares the budget fulfilling its apparent requirements but the most important target 'common masses' is ignored at various levels to provide them elementary facilities of life. PBS conveys the information quantitatively not qualitatively while IBS directly comes to the point and brings out innovative ideas to handle the situation.

These differences between Pakistani and Indian budget speeches are not due to any political or governmental reasons rather it is the nature of this document that budget of any country may have similarities and differences with other countries' budgets. These issues might be more or less in quantity but a fixed phenomenon of budgets is to have hidden meanings behind the declaration to achieve the immediate objectives of the government.

\section{References}

Chilton, P. (2003). Introduction. Journal of Politics and Language 2 (1): 1-3.

Dickinson, P. (2009). A systematic linguistics analysis of two prime mistrial speeches. The university of Birmingham edgbaston Birmingham.

Fairclough, N. (1993). Critical discourse analysis and the marketization of public discourse: The universities. Discourse and Society, 4(2), 133-168.

Idiagbon, M.S. (2010). Selected Nigerian Presidential Election Campaign Speeches: A Critical Discourse Analysis Perspective. Department of English, University of Ilorin, Ilorin. .

Luke, A. (1997). Theory and practice in critical science discourse. In L. Saha (Ed.), International encyclopedia of the sociology of education (pp. 50-56). NY: Pergamon.

Shayegh, K. (2012). Modality in political discourses of Obama and Luther. Department of ELT and General Linguistics, Ahar Branch, Islamic Azad University, Ahar, Iran.

Schaffner, C. (1996). Editorial: political speeches and discourse analysis, Current Issues in Language \& Society, 3, (3). pp. 201-204

Wang, J. (2010). Critical discourse analysis of Obama's speeches. Academy Publisher. 
The IISTE is a pioneer in the Open-Access hosting service and academic event management. The aim of the firm is Accelerating Global Knowledge Sharing.

More information about the firm can be found on the homepage:

http://www.iiste.org

\section{CALL FOR JOURNAL PAPERS}

There are more than 30 peer-reviewed academic journals hosted under the hosting platform.

Prospective authors of journals can find the submission instruction on the following page: http://www.iiste.org/journals/ All the journals articles are available online to the readers all over the world without financial, legal, or technical barriers other than those inseparable from gaining access to the internet itself. Paper version of the journals is also available upon request of readers and authors.

\section{MORE RESOURCES}

Book publication information: http://www.iiste.org/book/

Recent conferences: http://www.iiste.org/conference/

\section{IISTE Knowledge Sharing Partners}

EBSCO, Index Copernicus, Ulrich's Periodicals Directory, JournalTOCS, PKP Open Archives Harvester, Bielefeld Academic Search Engine, Elektronische Zeitschriftenbibliothek EZB, Open J-Gate, OCLC WorldCat, Universe Digtial Library, NewJour, Google Scholar

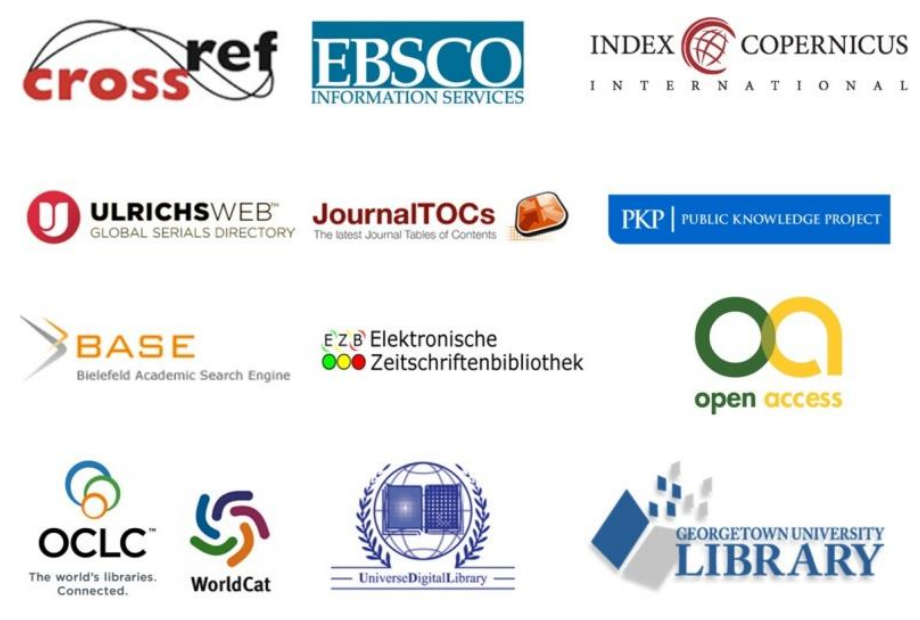

